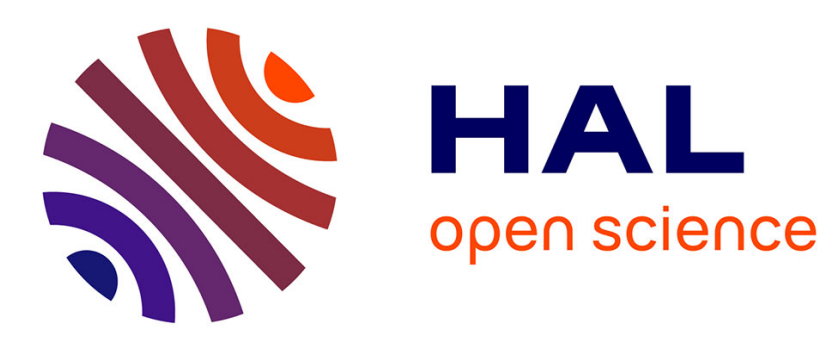

\title{
The surface diffusion of tungsten at very high temperatures
}

\author{
Vu Thien Binh, R. Uzan, M. Drechsler
}

\section{To cite this version:}

Vu Thien Binh, R. Uzan, M. Drechsler. The surface diffusion of tungsten at very high temperatures. Journal de Physique Lettres, 1978, 39 (21), pp.385-388. 10.1051/jphyslet:019780039021038500 . jpa00231523

\section{HAL Id: jpa-00231523 https://hal.science/jpa-00231523}

Submitted on 1 Jan 1978

HAL is a multi-disciplinary open access archive for the deposit and dissemination of scientific research documents, whether they are published or not. The documents may come from teaching and research institutions in France or abroad, or from public or private research centers.
L'archive ouverte pluridisciplinaire HAL, est destinée au dépôt et à la diffusion de documents scientifiques de niveau recherche, publiés ou non, émanant des établissements d'enseignement et de recherche français ou étrangers, des laboratoires publics ou privés. 


\title{
THE SURFACE DIFFUSION OF TUNGSTEN AT VERY HIGH TEMPERATURES
}

\author{
VU THIEN BINH, R. UZAN and M. DRECHSLER $\left(^{*}\right)$
}

Département de Physique des Matériaux (**), Université Lyon I, 43, boulevard du 11-Novembre-1918, 69621 Villeurbanne, France

(Reçu le 3 juillet 1978, révisé le 21 août 1978, accepté le 14 septembre 1978)

\begin{abstract}
Résumé. - Le coefficient d'auto-diffusion de surface du tungstène est déterminé pour des températures extrêmement élevées $(3000-3600 \mathrm{~K}$ ) à partir des résultats expérimentaux de van der Mast (pointe chauffée par laser) et en utilisant notre théorie sur l'évolution des pointes par diffusion de surface et évaporation libre. L'énergie d'activation dans cette gamme de températures est très supérieure à celle obtenue pour les basses températures, indiquant ainsi un changement dans le mécanisme de diffusion.
\end{abstract}

\begin{abstract}
The surface self-diffusion coefficient of tungsten in the region of extreme high temperatures $(3000-3600 \mathrm{~K})$ is determined from van der Mast experimental data on laser heated tips using our theory on tip evolution by capillarity forces and evaporation. In contrast to previous results at less high temperatures, the new results show a slope change in the $\log D_{s}$ versus $1 / T$ curve indicating a change of the diffusion mechanism with increasing temperature.
\end{abstract}

1. Introduction. - Recent studies of surface selfdiffusion of metals have shown that certain previous data show important errors in those temperature region where free evaporation is not negligible $[1,2$, 24]. This has been confirmed for molybdenum for temperatures up to 0.85 of the melting temperature $T_{\mathrm{M}}$ using the tip evolution technique [2].

In the case of tungsten, measurements in the high temperature region $(3000 \mathrm{~K}<T<3600 \mathrm{~K})$ where evaporation occurs have not been made so far, because such high temperatures are not obtained on field emitter tips with the usual type of heating, i.e. Joule heating and heat conduction [3]. Recently - in the course of a special field emission gun development van der Mast [4] has heated W tips by a laser in the range between 3000 and $3600 \mathrm{~K}$. In this paper, we show that the experimental results of this author can be interpreted using our theoretical results on tip evolution in the presence of evaporation $[2,5]$ which enables a determination of the surface diffusion coefficient of tungsten at extreme high temperatures.

(*) Centre de Recherche sur les Mécanismes de la Croissance Cristalline, C.N.R.S., Université d'Aix-Marseille, St-Jérôme, 13397 Marseille, France.

(**) Associé au C.N.R.S. (LA 172).
2. Experimental results. - Van der Mast's experimental device is schematically represented in figure 1. The tungsten tip was heated with an $1.5 \mathrm{~W}$ laser and the tip temperature was determined by measuring the total electron (Schottky) emission from the tip. To maintain a stable temperature - (the main effects causing undesired instabilities are fluctuations of the laser beam intensity and movements of the air in the laser beam) - two mechanisms are used (1) the tip

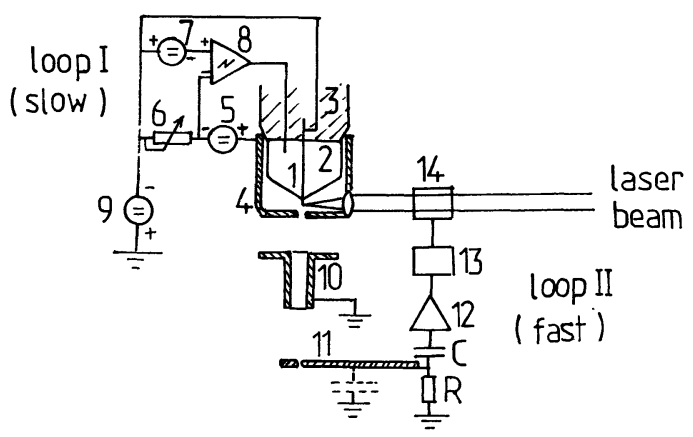

FIG. 1. - The laser beam heated tip device with the two feedback loops $; 1$. cathode wire $; 2$. transport system $; 3$. insulator $; 4$. first anode $; 5$. first anode voltage supply ; 6 . measuring resistor; 7. reference voltage; 8 . integrator; 9 . HV supply; 10 . second anode; 11. insulated aperture ; 12 . amplifier ; $13.40 \mathrm{MHz}$ driver ; 14. modulator head (Fig. 2.5.1 of ref. [4]). 
transport for the lower frequencies (feedback loop I of Fig. 1) and (2) the modulation of the laser beam for the high frequencies (feedback loop II of Fig. 1). To control the cleanliness of the tip surface, a fluorescent screen was placed in front of the tip and field emission pattern can be observed.

As the aim of van der Mast [4] is to have a laser heated Schottky emission gun for electron microscopy, the tungsten tip was heated by the focused laser beam near the melting point typically from about $3100 \mathrm{~K}$ to $3600 \mathrm{~K}$. From the observations of the field electron patterns at these high temperatures [4] the tip surface was clean even the vacuum was only about $10^{-5}$ to $10^{-4}$ torr.

Two significant facts emerged from the experiments :

1) the tip evolved to a stable form (Fig. 2) in about 5 minutes;

2) the radius of curvature of the tip was quite independent of the temperatures $(3100-3600 \mathrm{~K})$ and always remained about $0.3 \mu \mathrm{m}$ (Fig. 2).

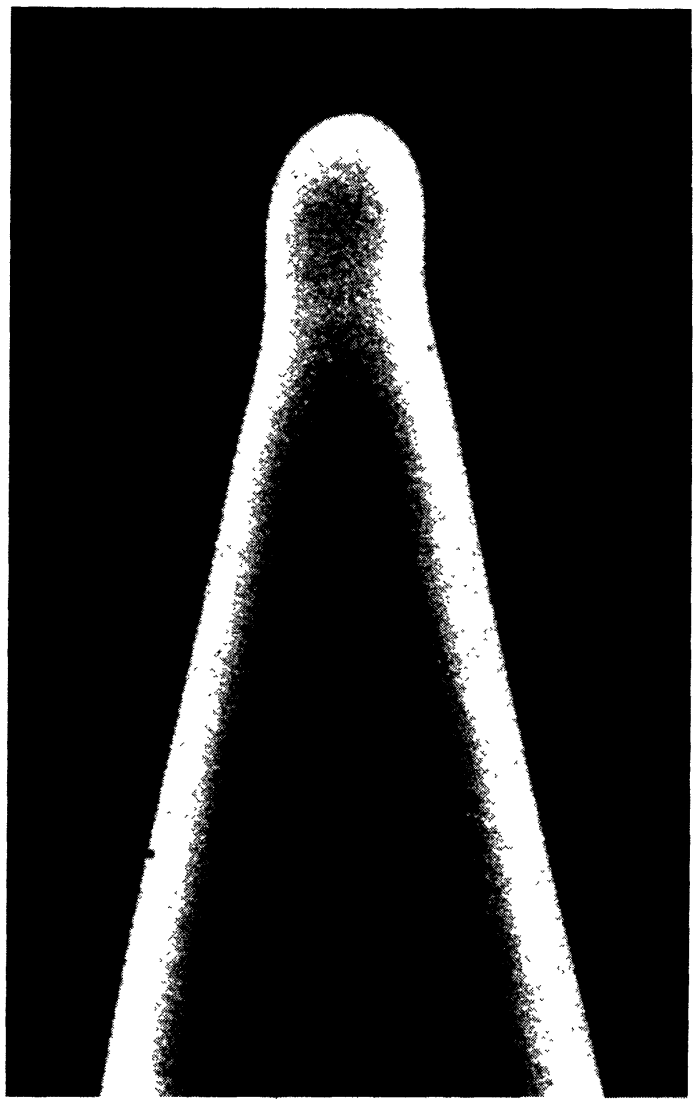

Fig. 2. - Scanning electron micrograph of the limiting profile of a W tip with an apex radius of $0.3 \mu \mathrm{m}$ (from ref. [4]).

3. Interpretation. - A qualitative partial explanation of these results was given by van der Mast in his thesis by introducing the free evaporation of $\mathrm{W}$; but he did not calculate values of $D_{s}$ or of the evaporation rate.
However, a theory on the tip apex evolution under the concomitant action of evaporation and surface diffusion had been presented and confirmed experimentally $[5,6,2]$. We recall it very briefly here : the basic differential equation describing the morphological changes of the tip under the simultaneous action of evaporation and surface diffusion by capillarity forces is :

$$
\frac{\mathrm{d} n}{\mathrm{~d} t}=\frac{\gamma D_{s} \Omega^{2} n_{0}}{y k T} \frac{\delta}{\delta s}\left[y\left(\frac{\delta K}{\delta s}\right)\right]-\Omega p\left(2 \pi m_{\mathrm{a}} k T\right)^{-1 / 2}
$$

where $\mathrm{d} n / \mathrm{d} t$ is the normal velocity of a surface element, $\gamma$ the surface energy (assumed isotropic), $D_{s}$ the surface diffusion coefficient (assumed isotropic), $n_{0}$ the total number of adsorption sites per unit area, $k$ Boltzmann's constant, $T$ the absolute temperature, $m_{\mathrm{a}}$ the atomic mass, $p$ the vapour pressure, $y$ the distance of a surface element to the tip axis, $s$ the surface arc length, $K$ the surface curvature, $\Omega$ the atomic volume.

The theory predicts for large cone angle tip evolution in presence of evaporation :

1) the tip profile evolves to a limiting profile, a pseudostationary profile which is independent of the initial radius value;

2) the limiting apex radius $R_{1}$ is given by :

$$
R_{1}=\left[0.63 . A_{\alpha} \gamma D_{s} p^{-1} \cdot \Omega^{1 / 3} m_{\mathrm{a}}^{1 / 2}(k T)^{-1 / 2}\right]^{1 / 3}
$$

where $A_{\alpha}$ is a known geometrical factor [7].

These predictions were experimentally confirmed with a Mo tip up to 0.85 of the melting temperature $T_{M}$ [2]. Van der Mast's experimental results [4] can be regarded as another confirmation of our predictions on the existence of limiting radii and profiles.

\section{Surface diffusion of $W$ at very high temperature. -} From the theory $[2,6]$, the surface diffusion coefficient and evaporation rate can be determined if the variation with time of the tip radius is known; this has been shown for Mo [2]. If only the limiting profile is measured, which corresponded to van der Mast's experiment, the surface diffusion coefficient $D_{s}$ can be calculated from equation (2). For the determination of $D_{s}$ we take $\gamma=2500 \mathrm{erg} . \mathrm{cm}^{-2} ; A_{\alpha}=1.5$ [7]; and for the vapour pressure $p$ the data of the equation :

$$
\log _{10} p=A T^{-1}+B \log _{10} T+C T+D T^{2}+E
$$

with $p$ in torr, $A, B, C, D$ and $E$ are parameters given by reference [8].

The results for $D_{\mathrm{e}}$ are plotted in figure 3, which gives the following values for the pre-exponential term $D_{0}$ and the activation energy $Q_{s}$

$$
\begin{aligned}
&\left(D_{s}=D_{0} \exp \left(-Q_{s} / k T\right)\right): \\
& D_{0}=9.5 \times 10^{7} \mathrm{~cm}^{2} . \mathrm{s}^{-1}
\end{aligned}
$$




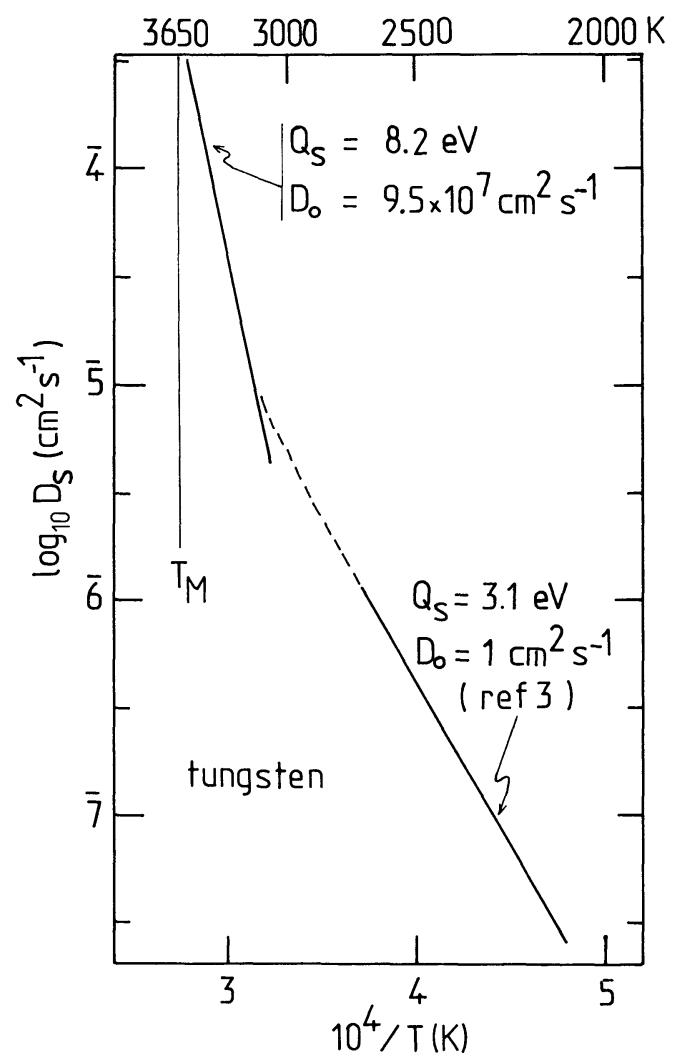

FIG. 3. - Surface self-diffusion coefficients of tungsten.

and

$$
Q_{s}=8.2 \mathrm{eV}\left(187 \mathrm{kcal} \cdot \mathrm{mole}^{-1}\right) .
$$

The value of $D_{s}$ extrapolated to the melting point $(3650 \mathrm{~K})$ is $5.6 \times 10^{-4} \mathrm{~cm}^{2} \cdot \mathrm{s}^{-1}$.

5. Discussion. -5.1 The combination of the data of $D_{s}$ for extreme high temperatures $(3100-3600 \mathrm{~K})$ with data at less high temperatures $(2$ 100-2 $800 \mathrm{~K})$ measured by the same technique [3] indicates a change of the slope of $\log D_{s}$ versus $1 / T$ curve (Fig. 2). This is new for tungsten as far as we know, but such a slope change is known for other systems as for example $\mathrm{Cu}$ [1] and Mo [2]. In agreement with the explanation for other metals [9], we explain the slope change as a change of the mechanism of surface diffusion. In the lower temperature region the diffusion occurs as jumps of surface atoms into neighbouring sites. In the higher temperature region the diffusing atoms are no longer in well localized sites and they migrate over large distances not only as single atoms but also as clusters. Between the two regions is an intermediate region where both mechanisms exist with a slow variation of their relative importance.

5.2 By comparing our $D_{s}$ values with former ones (for example Refs. [10, 11]), it should not be overlooked that only in our study the evaporation influence is considered, an influence which is very important in the higher temperature region [24].
5.3 The problem of surface contamination has to be considered as the experiments were made in a vacuum of only $10^{-5}$ torr. Fortunately at the temperature of the experiments $(T \gtrsim 3100 \mathrm{~K})$ the rate of desorption of impurities $\left(\mathrm{C}, \mathrm{O}_{2}, \ldots\right)$ is certainly greater than the rate of arrival by adsorption or diffusion. The impurities coverage is therefore pratically zero as the cleanliness of the surface was experimentally controlled by TF-emission images [4].

5.4 In order to describe the diffusion data of different metals by one function, Neumann and Hirschwald have represented the reduced activation energy of surface self-diffusion $Q_{s} / T_{\mathrm{M}}$ on reduced temperature $T / T_{\mathrm{M}}$ measured by tip techniques where the surface cleanliness is controlled [12] (Fig. 4). The

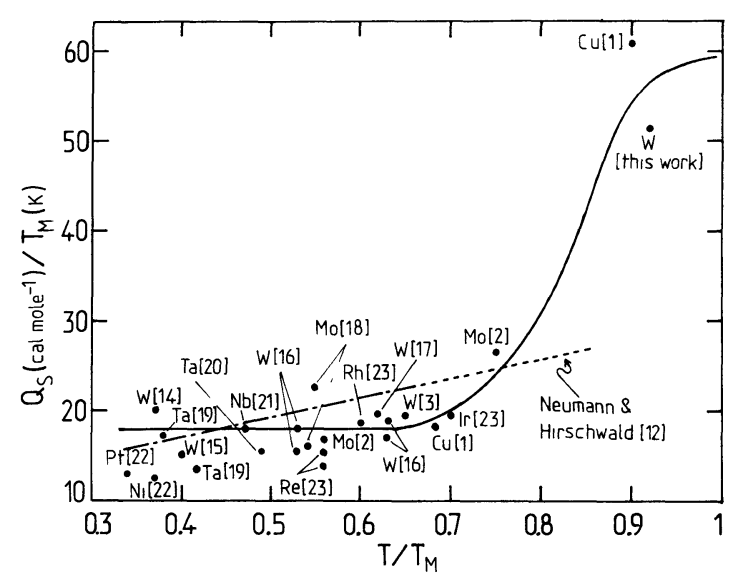

FIG. 4. - Reduced activation energy $Q_{s} / T_{\mathrm{M}}$ versus reduced temperature $T / T_{\mathrm{M}}$. Only results obtained by tip evolution techniques are presented.

data presented by these authors in 1972 concerned only the lower temperatures $T / T_{\mathrm{M}}<0.7$. In figure 4 we have added (besides a few other corrections) the 3 points of the higher temperature region $T / T_{\mathrm{M}} \gtrsim 0.75$, i.e. the value of figure 3 and two other data $(\mathrm{Mo}, \mathrm{Cu})$ we obtained [1,2]. The curve which connects the experimental points shows (in contrast to the linear curve of 1972) a drastic change at about $0.8 T_{\mathrm{M}}$ indicating the discussed change of the diffusion mechanism. Previously slope changes of the surface diffusion were found for f.c.c. but not for b.c.c. metals and it was supposed that this difference is of general importance [13]. The results presented in figure 3 and 4 show that this hypothesis is not correct. The slope change, i.e. the change of the diffusion mechanism with increasing temperature, exists also in the case of b.c.c. metals as W or Mo.

Acknowledgment. - We would like to thank Dr. van der Mast (Delft/Eindhoven) for his kind permission to use his data and for explaining details of his experiments. 


\section{References}

[1] Vu Thien Binh, Piquet, A., Roux, H., Uzan, R. and Drechsler, M., J. Physique Lett. 35 (1974) L-91.

[2] Vu Thien Binh, Uzan, R. and Drechsler, M., Surf. Sci. 57 (1976) $118 ; 60$ (1976) 13.

[3] Piquet, A., Roux, H., Vu Thien Binh, Uzan, R. and DRECHSLER, M., Surf. Sci. 44 (1974) 575.

[4] VAN DER MAST, K. D., A laser heated Schottky emission gun for electron Microscope, Thesis 1975, Technische Hogeschool, Delft, Holland; Private Communication.

[5] Vu Thien Binh, Piquet, A., Roux, H., Uzan, R. and DRECHSLER, M., Surf. Sci. 44 (1974) 598.

[6] Vu Thien Binh, Heyde, P., Uzan, R'. and Drechsler, M., 24th Inter. Field Emission Symp. (1977), Oxford, England.

[7] Nichols, F. A. and Mullins, W. W., J. Appl. Phys. 36 (1965) 1826.

[8] HoniG, R. E. and Kramer, D. A., Vapor pressures data, RCA (1970) pp. 505-531.

[9] Bonzel, H. P., Surf. Sci. 21 (1970) 45 ; in Structure and properties of metal surfaces, S. Shimodaira, Ed. Vol. 1 (Maruzen Co Ltd, Tokyo) 1973.

[10] Allen, B. C., Trans. AIME 236 (1966) 915; 245 (1969) 1621.

[11] Bowden, F. P. and Singer, K. E., Nature 222 (1969) 977.

[12] NeumanN, G. and Hirschwald, W., cited by G. Neumann and G. M. Neumann in Diffusion monograph series : surface self-diffusion of metals 1972, F. M. Wöhlbie Ed.

[13] RHEAD, G. E., Surf. Sci. 47 (1975) 207.

[14] Sokolskaya, I. L., Izvest. Akad. Nauk, Ser. Fiz. Khim. 20 (1956) 1151.

[15] Sokolskaya, I. L., Sov. Phys. Tech. Phys. 1 (1956) 1147.

[16] Bettler, P. C. and Charbonnier, F. M., Phys. Rev. 119 (1960) 85.

[17] Barbour, J. P., Charbonnier, F. M., Dolan, W. W., Dyke, W. P., Martin, E. E. and Trolan, J. K., Phys. Rev. 117 (1960) 1452.

[18] Sokolskaya, I. L., Neumann, H. and Kloze, E., Sov. Phys. Solid State $6(1964 / 65)$ 1126, 1369.

[19] Pantov, D. M. and Sokolskaya, I. L., Sov. Phys. Solid State $10(1968 / 69) 1941$.

[20] Drundarov, N., Bober, K. and Kunov, V., Izvest. Inst. Elecktr. Bulg. Akad. Nauk 3 (1967) 27.

[21] Odishariya, G. A., Sov. Phys. Solid State 10 (1968/69) 1130.

[22] Melmed, A. J., J. Appl. Phys. 38 (1967) 1885.

[23] Bettler, P. C. and Barnes, G. M., Surf. Sci. 10 (1968) 165.

[24] Vu Thien Binh, Moulin, Y., Uzan, R., Drechsler, M., Surf. Sci. (accepted for publication). 